\title{
Epstein-Barr Virus Reactivation in Critically Ill Immunocompetent Patients
}

\author{
Nicolas Libert ${ }^{1}$, Christine Bigaillon², Cyrus Chargari ${ }^{3}$, Mourad Bensalah ${ }^{1}$, Violaine Muller ${ }^{1}$, \\ Stéphane Merat ${ }^{4}$, Stéphane de Rudnicki ${ }^{1}$
}

Background: Herpes viruses can be reactivated among immunocompetent patients in intensive care unit (ICU). Cytomegalovirus (CMV) and herpes simplex virus (HSV) have been the most studied. We hypothesized that Epstein-Barr virus (EBV) could also be reactivated in immunocompetent patients during their stay in ICU and that this would be associated with morbidity and mortality.

Methods: This prospective observational study included 90 patients with an ICU stay of $\geq 5$ days. CMV and HSV were considered when clinically suspected and DNA was researched in blood or bronchoalveolar lavage (BAL). EBV DNA viral quantification was performed in the blood samples.

Results: $\quad$ EBV DNA was detected in blood of 61 patients (median length for positivity of 7.5 days). CMV DNA was detected in blood of 16 patients (median length for positivity of 13.5 days) and BAL of 6 patients. HSV1 DNA was detected

\section{At a Glance Commentary}

Scientific background of the subject

Herpes viruses can be reactivated among immuncompetent patients in intensive care unit. However, few data are available on the role of Epstein-Barr virus $(\mathrm{EBV})$ reactivation and its potential pathogenicity.

\section{What this study adds to the field}

This study confirms that EBV DNA is detected in peripheral blood of numerous ICU patients and suggests that EBV reactivation is associated with morbidity and mortality.

in the BAL of 28 patients (median length for positivity of 7.5 days). Nineteen patients had no viral reactivation, 1 experienced only CMV, 32 had only EBV, 5 had only HSV, 6 had EBV and CMV, 14 had EBV and HSV, and 9 patients reactivated three viruses. Mortality was higher among patients with EBV reactivation (33/61 vs. $7 / 25, p=0.02)$. Length of stay ( 21 vs. 10 days, $p<0.001)$ and length of mechanical ventilation $(15$ vs. 7 days, $p<0.001)$ were higher among patients with EBV reactivation.

Conclusions: This study shows that EBV DNA is detected in blood of diverse ICU patients with $\geq 5$ days of stay and that it is associated with morbidity and mortality. Larger dynamic prospective studies are needed to correlate viral reactivation with immune system evolution during ICU stay and to determine the role of polyviral reactivations.

(Biomed J 2015;38:70-76)

Key words: cytomegalovirus, Epstein-Barr virus, herpes simplex virus, herpes virus, immunocompetent

$\mathrm{O}$ ver the past years, particular attention has been given to herpes virus reactivations among immunocompetent critically ill patients. Although the true pathogenicity of these reactivations is still debated, some authors have hypothesized that it could be related to specific immune failure caused by sepsis or multi-organ failure. Others have argued that it is only a marker of severity. There is increas- ing evidence that reactivation of cytomegalovirus (CMV) and herpes simplex virus (HSV) is associated with mortality or morbidity, mainly for ventilator-acquired pneumonia. ${ }^{[1,2]}$ CMV seroprevalence ranges from $40 \%$ to $95 \%$ depending on several factors, including age and geographic area. HSV1 seroprevalence is around $65 \%$ among the French population. Epstein-Barr virus (EBV) reactivation has been well docu-

From the ${ }^{1}$ Department of Anesthesiology and Critical Care, Val de Grâce Military Hospital, Paris, France; ${ }^{2}$ Department of Medical Microbiology and Virology, Bégin Military Hospital, Saint-Mandé, France; ${ }^{3}$ Department of Oncology and Radiation Therapy, Val de Grâce Military Hospital, Paris, France; ${ }^{4}$ Department of Anesthesiology and Critical Care, Bégin Military Hospital, Saint-Mandé, France Received: Aug. 06, 2013; Accepted: Mar. 04, 2014

Correspondence to: Dr. Libert Nicolas, Department of Anesthesiology and Critical Care, Val de Grâce Military Hospital, France. 74 Bd de Port Royal, 75005 Paris, France. Tel: 33-140514509; Fax: 33-140514608; E-mail: dr.libert.nicolas@ gmail.com

DOI: $10.4103 / 2319-4170.132905$ 
mented in case of immunodeficiency as well as associated pathogenicity. More recently, it has been associated with stress among draftees and astronauts or even during malaria infection in children ${ }^{[3-5]}$ Furthermore, several in vitro and in vivo investigations have highlighted a relationship between CMV infection and EBV reactivation, suggesting possible synergic pathogenicity. ${ }^{[6-8]} \mathrm{CMV}$ can also impair the immune response to EBV during aging. ${ }^{[9]} \mathrm{EBV}$ is found latent in at least $90-95 \%$ of people, which is the highest rate for herpes viruses. Several works have reported the detection of EBV DNA in the lower respiratory tract or in the blood of intensive care unit (ICU) patients without showing specific pathogenesis except inflammation. ${ }^{[10,11]}$ During reactivation, EBV produces an interleukin-10 (IL-10) homolog, which is able to disturb the immune response, particularly, the activity of natural killer (NK) and CD4+ T cells. ${ }^{[12]}$ EBV also produces proteins that impair the production of cytokines such as interferon, mainly during the lytic phase. ${ }^{[13-15]}$ EBV induces diverse immune modifications. ${ }^{[16]}$ This could have important consequences on the host response to other pathogens, particularly during multiple viral infection or reactivations. Only a few case reports have described pneumonia potentially caused by EBV in immunocompetent patients. However, immune suppression has been suggested to be the cause of viral reactivation of CMV and HSV. ${ }^{[17]}$ We hypothesized that EBV could also be reactivated in critically ill immunocompetent patients and that this could be associated with mortality and morbidity. Therefore, we conducted a pilot prospective study in order to investigate the issue of EBV reactivation using quantification of viral DNA. We focused on patients who were tested for CMV reactivation according to our department's rules.

\section{METHODS}

\section{Patients}

This prospective study was performed from 30 November 2010 to 31 May 2011 in a 12-bedded medico-surgical ICU.

CMV DNA is routinely quantified in our department for the following high-risk patients with or without clinical symptoms of specific viral disease: (1) in case of persistent organ failure after 5 days of ICU stay; (2) at admission for patients transferred to our ICU after at least 5 days of hospitalization in another ICU and with at least two organ failures at admission; and (3) among the patients transferred to ICU after a prolonged hospital stay ( $\geq 15$ days), with at least one organ dysfunction. Polymerase chain reaction (PCR) is performed twice weekly on Mondays and Fridays. HSV and CMV were also quantified in bronchoalveolar lavage (BAL) at admission in the patients transferred from another ICU for acute respiratory distress syndrome (ARDS) evolving at least for
5 days, for patients admitted after progressive lung deterioration despite adequate antibiotic treatment (more than $96 \mathrm{~h}$ of treatment), and for any nosocomial pneumonia acquired in intensive care after a stay of 5 days that is associated with at least one organ failure (with or without mechanical ventilation). Patients' characteristics were prospectively recorded.

\section{Study design}

For this study, EBV DNA quantification was performed in the same blood sample of patients for whom CMV quantification was performed. Patients were not included if there were minor or pregnant, had hematological disease or EBV-induced malignancy (EBV-induced lymphomas, nasopharyngeal carcinoma, and gastric carcinoma), or in case of having immune deficit (defined as having immunodeficiency syndrome and having received immunosuppressive therapies in the last 3 months or more than 1 month of corticosteroid therapy). The study was approved by the regional ethics committee (Comité de Protection des Personnes Ile de France VI - Groupe Hospitalier Pitié Salpètrière) which waived the need for written consent.

\section{DNA quantification using PCR}

CMV DNA and EBV DNA were quantified in $200 \mu \mathrm{l}$ of whole blood stored at $-20^{\circ} \mathrm{C}$. HSV1 DNA and HSV2 DNA were quantified in $200 \mu \mathrm{l}$ of BAL stored at $+4^{\circ} \mathrm{C}$, both using commercial real-time PCR assay (CMV R-gene ${ }^{\circledR}$, EBV R-gene ${ }^{\circledR}$, and HSV1-HSV2 R-gene ${ }^{\circledR}$ PCR; Argene ${ }^{\circledR}$, Verniolle, France) according to the manufacturer guidelines. Quantitative PCR levels were reported as copies per milliliter of whole blood. EBV DNA quantification was considered positive if it showed $\geq 250$ copies per milliliter. Patients with positive EBV PCR were considered as having reactivation.

\section{Serology}

CMV IgG indicating prior CMV infection was assessed using an immunochemiluminescent assay (Cobas e601- CMV IgG, Craponne; Roche ${ }^{\circledR}$ Meylan), and Epstein Barr nuclear antigen (EBNA)-IgG and virus capsid antigen (VCA)-IgG indicating prior EBV infection were assessed using a fluorescent assay (VIDAS EBV VCA IgG and VIDAS EBV EBNA IgG; bioMérieux ${ }^{\circledR}$, France). The assay was performed and interpreted according to the manufacturer's recommendations. Patients with CMV IgGs were considered CMV seropositive. Patients with VCA and/or EBNA IgGs were considered EBV seropositive.

\section{Follow-up}

The duration of catecholamine's support, duration of dialysis support in ICU, duration of mechanical ventilation, and death at day 28 and day 90 were recorded. 


\section{Statistical analysis}

As there are scarce data about EBV reactivation in critically ill patients, we based our calculation on the data collected from studies of CMV and HSV and decided to include 90 patients over a study period of 6 months.

Data were expressed as median (interquartile). To explore the relationship between EBV and CMV, two analyses comparing the populations with and without EBV reactivation were planned: the first one with EBV seropositive patients and the second one with both EBV and CMV seropositive patients.

Data were presented as median (interquartile). Comparison between groups reactivating and not was performed using non-parametric tests as appropriate (Mann-Whitney test for continuous variables and Fisher's exact test for categorical variables). Collinearity test was performed to examine the collinearity between independent variables. Variables with $p \leq 0.1$ in univariate analysis were included in a multivariate logistic regression model (backward variable selection procedure based on Akaike information Criterion (AIC)). Analyses were performed with R software (http:// cran.r-project.org) and the package R-Excel. Also, $p<0.05$ was considered as significant.

\section{RESULTS}

\section{Patients and patterns of seropositivity}

Ninety EBV-positive patients were enrolled in this study from 143 patients with more than 5 days length of ICU stay. Two patients were excluded because of doubtful EBV serology and two patients were secondarily excluded because of unknown immunosuppressive state at admission. Among the 86 analyzable patients, 53 were seropositive for CMV (61.6\%) [Figure 1]. Patients' characteristics are presented in Table 1. Data of patients positive for both EBV and CMV are described in Table 2.

\section{Viral reactivation}

EBV DNA was detected in the blood of 61 patients with a median length for positivity of 7.5 days (2-15 days). CMV DNA was detected in the blood sample of 16 patients with a median length for positivity of 13.5 days (2.5-23.5 days). Forty-one patients had BAL with viral research. CMV DNA was detected in the BAL of $6 / 41(14.6 \%)$ patients, with 2 of them without CMV DNA in blood (2 patients had CMV DNA both in blood and BAL and 14 had it only in blood). HSV1 DNA was detected in the BAL of 28/41 (68.3\%) patients with a median length for positivity of 7.5 days (3-14.5 days). HSV2 was never detected. Nineteen patients experienced no viral reactivation at all, 1 patient experienced

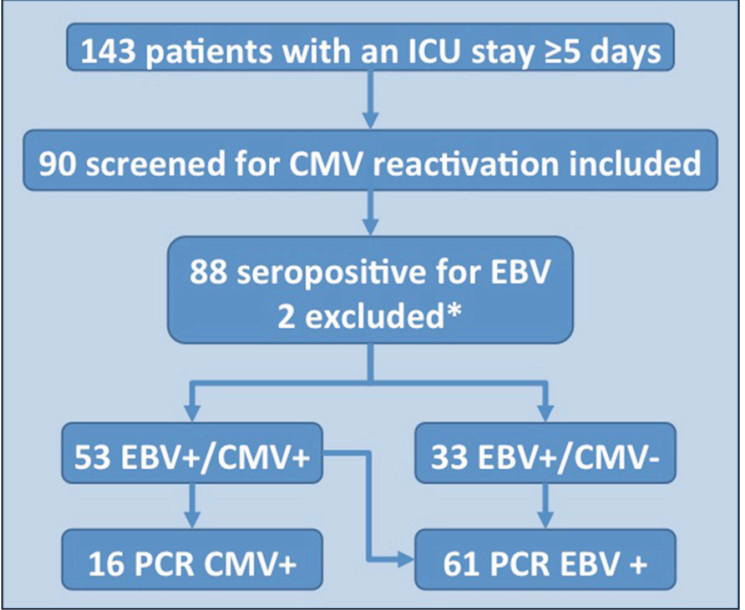

Figure 1: Flow diagram of the study. $\mathrm{EBV}+/ \mathrm{CMV}+=$ patients seropositive for $\mathrm{EBV}$ and $\mathrm{CMV}$; $\mathrm{EBV}+/ \mathrm{CMV}=$ patients seropositive for $\mathrm{EBV}$ alone; PCR CMV+ = positive PCR for CMV; PCR EBV+ = Positive PCR for EBV; *2 patients were excluded due to unknown immunosuppression at admission; 86 patients were analyzed.

Table 1: Patients' characteristics at admission

\begin{tabular}{|c|c|c|c|}
\hline $\begin{array}{l}\text { EBV seropositive } \\
n=86\end{array}$ & $\begin{array}{c}\text { Reactivation } \\
n=61\end{array}$ & $\begin{array}{c}\text { No reactivation } \\
n=25\end{array}$ & $p$ value \\
\hline Age & $69(58-78)$ & $66(51-75)$ & 0.142 \\
\hline Gender: female/male & $9 / 52$ & $8 / 17$ & 0.068 \\
\hline Provenance & & & 0.089 \\
\hline Other ICU & 20 & 5 & \\
\hline Hospital & 14 & 5 & \\
\hline Emergency & 6 & 0 & \\
\hline Other hospital & 5 & 1 & \\
\hline Home & 5 & 5 & \\
\hline Operating room & 2 & 5 & \\
\hline War casualties & 3 & 2 & \\
\hline Other & 6 & 2 & \\
\hline Reason for ICU admission & & & 0.011 \\
\hline Respiratory & 23 & 2 & \\
\hline Neurologic & 9 & 8 & \\
\hline Infection/sepsis & 13 & 5 & \\
\hline Postsurgical & 3 & 4 & \\
\hline Cardiac failure & 2 & 3 & \\
\hline Other & 11 & 3 & \\
\hline \multicolumn{4}{|l|}{ History of } \\
\hline Atrial fibrillation & 22 & 9 & 0.805 \\
\hline Arteriopathy & 6 & 2 & 0.715 \\
\hline COPD & 2 & 1 & 0.919 \\
\hline Cirrhosis & 4 & 2 & 0.884 \\
\hline Coronary disease & 7 & 3 & 0.960 \\
\hline Diabetes & 10 & 4 & 0.852 \\
\hline Chronic renal failure & 7 & 1 & 0.242 \\
\hline Hypertension & 29 & 13 & 0.958 \\
\hline Chronic cardiac failure & 5 & 0 & 0.126 \\
\hline Cancer & 26 & 6 & 0.067 \\
\hline SAPS II & $60(44-71)$ & $56(38-71)$ & 0.284 \\
\hline
\end{tabular}

Data are presented as effectives or as median (interquartile). Abbreviations: ICU: Intensive care unit; COPD: Chronic obstructive pulmonary disease; SAPS: Simplified acute physiology score 
Table 2: Population of double seropositive patients according to EBV reactivation

\begin{tabular}{|c|c|c|c|}
\hline $\begin{array}{l}\mathrm{EBV}+/ \mathrm{CMV}+ \\
(n=53)\end{array}$ & $\begin{array}{c}\mathrm{EBV} \\
\text { reactivation } \\
(n=38)\end{array}$ & $\begin{array}{l}\text { No EBV } \\
\text { reactivation } \\
(n=15)\end{array}$ & $p$ value \\
\hline Age (years) & $69(58.3-75)$ & $72(58.6-77.5)$ & 0.480 \\
\hline \multicolumn{4}{|l|}{ Gender } \\
\hline Female/male & $7 / 31$ & $4 / 11$ & 0.505 \\
\hline \multicolumn{4}{|l|}{ Provenance } \\
\hline Other ICU & 16 & 4 & 0.034 \\
\hline Hospital & 11 & 2 & \\
\hline Other hospital & 6 & 1 & \\
\hline SAMU & 3 & 2 & \\
\hline Operating room (hospital) & 0 & 5 & \\
\hline Others & 2 & 1 & \\
\hline \multicolumn{4}{|l|}{ Reason for ICU admission } \\
\hline Respiratory & 17 & 1 & 0.035 \\
\hline Neurologic & 6 & 3 & \\
\hline Infectious disease/sepsis & 5 & 3 & \\
\hline Postsurgical & 2 & 3 & \\
\hline Cardiac failure & 1 & 3 & \\
\hline Others & 7 & 2 & \\
\hline SAPS II & $62(48.8-71.8)$ & $60(33-71)$ & 0.198 \\
\hline Pneumonia (\%) & 84.2 & 53.3 & 0.058 \\
\hline Including VAP & 60.5 & 33.3 & 0.074 \\
\hline Acute renal failure $(\%)$ & 60.5 & 50.0 & 0.360 \\
\hline Dialysis support (\%) & 44.4 & 40.0 & 0.889 \\
\hline Dialysis support (days) & $0(0-4.8)$ & $0(0-6)$ & 0.439 \\
\hline Catecholamine support (days) & $5(0-9.8)$ & $4(1-7)$ & 0.261 \\
\hline Transfusion & 71.1 & 66.6 & 0.754 \\
\hline Length of MV (days) & $19(8.3-32)$ & $8(2-11)$ & 0.005 \\
\hline Length of stay in ICU (days) & $23(10-41)$ & $14(8-20.5)$ & 0.046 \\
\hline Status on day $28(\%)$ & 28.9 & 20.0 & 0.506 \\
\hline Status on day $90(\%)$ & 60.5 & 20.0 & 0.008 \\
\hline Number of PCR EBV & $4(2-6.8)$ & $3(1-4)$ & 0.040 \\
\hline Length for positivity & $8(2.3-18)$ & & \\
\hline Number of PCR CMV & $4(2-6.8)$ & $2(1.5-4)$ & 0.030 \\
\hline Length for positivity & $15(2-25)$ & $5(5-5)$ & 0.331 \\
\hline Number of PCR HSV & $1(0-2)$ & $0(0-1)$ & 0.042 \\
\hline Length for positivity & $8(5-21)$ & $12(6.5-13)$ & 0.416 \\
\hline
\end{tabular}

Abbreviations: ICU: Intensive care unit; SAPS: Simplified acute physiology score; VAP: Ventilator acquired pneumonia; MV:

Mechanical ventilation; CMV: Cytomegalovirus; HSV: Herpes simplex virus; EBV: Epstein-barr virus; PCR: Polymerase chain reaction

only CMV reactivation, 32 patients had only EBV reactivation, 5 patients had only HSV reactivation, 6 patients had both EBV and CMV reactivation, 14 patients had EBV and HSV reactivation, and 9 patients reactivated all three viruses. None reactivated both CMV and HSV. Twenty-six patients reactivating EBV had low viral load ( $\leq 500$ copies $/ \mathrm{ml})$, while 7 patients had moderate load (500-1000 copies/ml) and 28 patients had high viral load (>1000 copies $/ \mathrm{ml}$ ).

In multivariate analysis, the risk factors for viral reactivation were found to be length of stay [odds ratio (OR): $1.08,95 \%$ confidence interval $(95 \% \mathrm{CI}): 1.02-1.15)$ and cancer (OR: 3.4, 95\% CI: 1.12-11.9].
PCR inhibitors were found in eight patients: Six EBV PCR (three with low viral load, one with high viral load for EBV, and two negatives), four HSV PCR (three negatives and one high viral load), and four CMV PCR (thee negatives and one low viral load).

Seven patients received antiviral therapy for respiratory worsening without bacterial or fungal pathogen, but with increasing viral loads: four received foscavir for synchronous CMV, HSV, and EBV reactivations, two received aciclovir for $\mathrm{HSV}$ reactivation, and one received gangiclovir for $\mathrm{CMV}$ reactivation.

The characteristics of patients according to the presence or absence of EBV reactivation among EBV seropositives are presented in Table 1 and among EBV/CMV seropositive patients in the Supplementary Material.

\section{Impact on outcome}

Patients with EBV reactivation had higher mortality rate and longer duration of mechanical ventilation and ICU stay [Table 2]. Mortality difference was significant only at 90 days either for $\mathrm{EBV}+/ \mathrm{CMV}-$ patients or for EBV+/ $\mathrm{CMV}+$ patients. There were no differences with respect to age, simplified acute physiology score II, and gender. Patients with EBV reactivation were more frequently admitted to the ICU because of respiratory failure. There was no significant relationship between the peak viral load and morbidity or mortality at day 90 . The viral load kinetics was different between survivors and non-survivors (Supplementary Material).

Patients with two or more herpes viruses' reactivation, whatever the subtype may be (EBV, CMV, or HSV), had longer duration of mechanical ventilation or ICU stay [Figure 2]. However, death rate at day 90 was not different.

\section{DISCUSSION}

This study highlights three points: (1) all tested patients had latent EBV infection; (2) most of them had virus reactivation while they were categorized as critically ill immunocompetent patients; and (3) reactivation was associated with higher morbidity and mortality.

EBV occurs worldwide and most people become infected during their lifetime. Most of the time, infection is asymptomatic, although it frequently causes infectious mononucleosis during adolescence. Infection is rarely complicated by organ dysfunction. EBV remains latent in B lymphocytes and in epithelial cells of the throat. It can rarely infect $\mathrm{T}$ lymphocytes and monocytes. EBV is known to be able to periodically reactivate, usually without any symptom. In such a case, the virus is found in saliva and/or blood. The triggering factors of reactivation are not known. Viral presence in blood has been debated as the whole-blood PCR also reflects the presence of clonal 


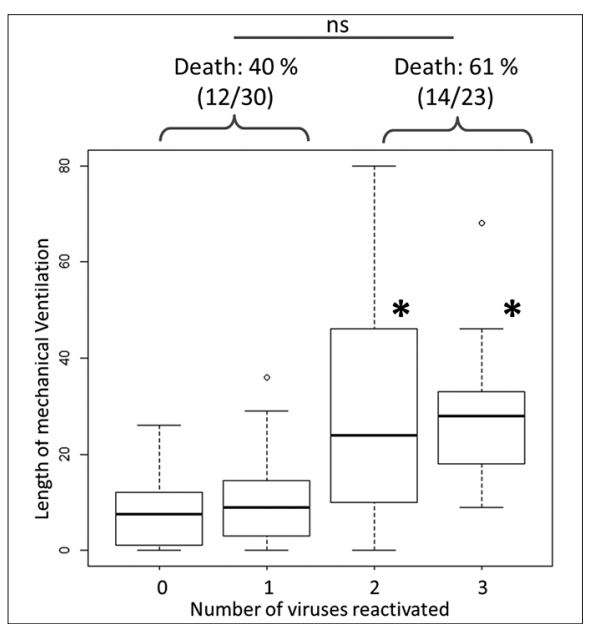

Figure 2: Length of mechanical ventilation according to the number of herpes viruses reactivated. $* p<0.05$ versus no or one virus reactivated. Death rates were compared between the group with 0 or one virus reactivated and the group with two or three viruses reactivated.

expansion of the infected B lymphocytes in response to an infection.

Pathogenicity of EBV load in blood (EBV DNAemia) is questionable as there is no threshold associated with induced diseases and some healthy people might have a low to moderate EBV load without any symptom. ${ }^{[18]}$ Several studies have described viral reactivation during prolonged stress events among immunocompetent patients..$^{[5,19,20]} \mathrm{EBV}$ reactivation has also been found to be associated with several autoimmune or cardiovascular diseases such as gastritis, rheumatoid arthritis, lupus, and multiple sclerosis. ${ }^{[21-23]}$ The pathophysiology of EBV reactivation remains uncertain. Recent data suggest that EBV could trigger inflammatory process through interleukin- 6 modulation. ${ }^{[24]}$ Other authors suggested that EBV could promote immune deficit of the $T$ cell response. ${ }^{[25]}$ In situations of immune perturbation, such as in most critically ill patients, this deficit could contribute to counteract the immune response. We observed higher incidence of pneumonia among people reactivating EBV, which could be explained as due to the impaired immunity. We also observed more candidemia in this group (10/61 vs. $1 / 25$, ns), and septic shocks were more frequent.

Several studies have highlighted an association between CMV reactivation and EBV reactivation in vitro and in vivo, while others have shown that the immune system, while decreasing through life, concentrates on latent viruses. ${ }^{[26-28]}$ Khan et al. reported that $\mathrm{CMV}+$ people had an accumulation of CMV-specific CD8 T cells and a decrease of EBV-specific CD8 cells. ${ }^{[9]}$ This difference increases with aging. Interestingly, they also found a fall in the proportions of functional CMV-specific CD8 cells and of EBV-specific CD8 cells over 60 years. We observed no relationship between EBV reactivation and CMV serologic status. Recently, Cicin-Sain et al., in their study in mice, have reported that CMV infec- tion resulted in an increase of CD8 T-cells and a weaker response to superinfection with influenza, HSV1, or West Nile Virus. ${ }^{[29]}$ Together, these data highly suggest an immune failure related to CMV status, particularly among old people. Possibly due to smaller population size, we found no significant relationship between age and reactivation. We also anticipated an earlier reactivation of CMV than EBV, but this was not the case. Only four patients reactivated $\mathrm{CMV}$ before $\mathrm{EBV}$, all with several reactivations, and this phenomenon was synchronous. We cannot exclude a "synergic" effect of latent viruses which could explain our results among poly-reactivating patients.

Respiratory failure and ARDS were overrepresented in our study. EBV was found to be associated with idiopathic pulmonary fibrosis and inflammation. ${ }^{[30,31]}$ Whether EBV reactivation could cause lung inflammation in critically ill patients has not been clearly studied. We recently performed quantitative EBV PCR in the BAL from five patients with ARDS and three of them had very high viral loads (unpublished data). These findings require further exploration to confirm a relationship.

We did not find any relationship between the outcome and viral load. Relevance of single viral loads is not so clear. ${ }^{[32]}$ We found different kinetic patterns between survivors and non-survivors. Patients who died increased their viral load while their state worsened. Globally, patients had an increasing viral load before they had symptoms of aggravation.

While some studies have involved herpes viruses in specific organ dysfunction, their potential pathogenicity is still debated. ${ }^{[33,34]}$ Even though evidence of active infection has been found in some studies, several questions remain: Which specific patient is at risk of developing such a disease? Should we treat them? In this case, what is the optimal timing for treating them? Should we consider high viral loads, rapid rise of viral load, associated organ dysfunction without other etiology, presence of cytopathic effect, or none? Independent of pathogenicity, viral reactivation is a marker of severe illness and reflects immune dysfunction. CMV has been associated with a poorer prognosis in ICU. Whereas CMV and HSV prevalence is intermediate, EBV's prevalence is very high and could be a model of immune failure.

No clear data is available for polyviral reactivation and on the interactions that could have viruses on each other. The significance of this phenomenon, as well as its linkage with global immune failure is questionable. This is a major concern for critically ill patients who have profound immunodeficiency. Lymphopenia and dysfunction of adaptive $\mathrm{T}$ cell immunity have not been extensively studied.

Our study has several limitations such as selection bias (all ICU patients were not included and systematic assays were not performed at scheduled time points in all included 
patients). Moreover, we have included a significant number of elderly patients and cancer patients (with past history of cytotoxic therapies such as chemo or radiotherapy), and thus, the results obtained may not reflect a more diverse and younger population. ${ }^{[35-37]}$ Another point is that we do not know if some patients had circulating DNA at admission. This could be important as it has been shown that healthy people without any disease could have circulating EBV with differences depending on gender or age. ${ }^{[18]}$ We have not found the exact cause of death for all the patients, but most of them died after limitation of life support for worsening condition or lack of improvement after a prolonged stay. We hypothesize that EBV could be reactivated due to immune suppression as it has been suggested for CMV and HSV. ${ }^{[12]}$

\section{Conclusion}

This study shows that EBV DNA is detected in peripheral blood of numerous ICU patients and that it is associated with morbidity and mortality. However, this is a small size for the study group and these results need to be confirmed in a larger cohort. Dynamic prospective studies in a more general ICU population are needed to correlate viral reactivation with immune system evolution during ICU stay and to determine the role of polyviral reactivations.

\section{REFERENCES}

1. Kalil AC, Florescu DF. Prevalence and mortality associated with cytomegalovirus infection in nonimmunosuppressed patients in the intensive care unit. Crit Care Med 2009;37:2350-8.

2. Luyt CE, Combes A, Deback C, Aubriot-Lorton MH, Nieszkowska A, Trouillet JL, et al. Herpes simplex virus lung infection in patients undergoing prolonged mechanical ventilation. Am J Respir Crit Care Med 2007;175:935-42.

3. Coskun O, Sener K, Kilic S, Erdem H, Yaman H, Besirbellioglu AB, et al. Stress-related Epstein-Barr virus reactivation. Clin Exp Med 2010;10:15-20.

4. Pierson DL, Stowe RP, Phillips TM, Lugg DJ, Mehta SK. EpsteinBarr virus shedding by astronauts during space flight. Brain Behav Immun 2005;19:235-42.

5. Donati D, Espmark E, Kironde F, Mbidde EK, Kamya M, Lundkvist A, et al. Clearance of circulating Epstein-Barr virus DNA in children with acute malaria after antimalaria treatment. J Infect Dis 2006;193:971-7.

6. Arcenas R, Widen RH. Epstein-Barr virus reactivation after superinfection of the BJAB-B1 and P3HR-1 cell lines with cytomegalovirus. BMC Microbiol 2002;2:20.

7. Mañez R, Breinig MC, Linden P, Wilson J, Torre-Cisneros J, Kusne S, et al. Posttransplant lymphoproliferative disease in primary Epstein-Barr virus infection after liver transplantation: The role of cytomegalovirus disease. J Infect Dis 1997;176:1462-7.

8. Aalto SM, Linnavuori K, Peltola H, Vuori E, Weissbrich B, Schubert J, et al. Immunoreactivation of Epstein-Barr virus due to cytomegalovirus primary infection. J Med Virol 1998;56:186-91.
9. Khan N, Hislop A, Gudgeon N, Cobbold M, Khanna R, Nayak L, et al. Herpesvirus-specific CD8 T cell immunity in old age: Cytomegalovirus impairs the response to a coresident EBV infection. J Immunol 2004;173:7481-9.

10. Friedrichs I, Bingold T, Keppler OT, Pullmann B, Reinheimer C, Berger A. Detection of herpesvirus EBV DNA in the lower respiratory tract of ICU patients: A marker of infection of the lower respiratory tract? Med Microbiol Immunol 2013;202:431-6.

11. Costa C, Elia M, Astegiano S, Sidoti F, Terlizzi ME, Solidoro P, et al. Quantitative detection of Epstein-Barr virus in bronchoalveolar lavage from transplant and nontransplant patients. Transplantation 2008;86:1389-94.

12. Jochum S, Moosmann A, Lang S, Hammerschmidt W, Zeidler R. The EBV immunoevasins vIL-10 and BNLF2a protect newly infected B cells from immune recognition and elimination. PLoS Pathog 2012;8:e1002704.

13. Cohen JI, Lekstrom K. Epstein-Barr virus BARF1 protein is dispensable for B-cell transformation and inhibits alpha interferon secretion from mononuclear cells. J Virol 1999;73:7627-32.

14. Morrison TE, Mauser A, Wong A, Ting JP, Kenney SC. Inhibition of IFN-gamma signaling by an Epstein-Barr virus immediate-early protein. Immunity 2001;15:787-99.

15. Salek-Ardakani S, Arrand JR, Mackett M. Epstein-Barr virus encoded interleukin-10 inhibits HLA-class I, ICAM-1, and B7 expression on human monocytes: Implications for immune evasion by EBV. Virology 2002;304:342-51.

16. Ning S. Innate immune modulation in EBV infection. Herpesviridae 2011;2:1.

17. Hotchkiss RS, Coopersmith CM, McDunn JE, Ferguson TA. The sepsis seesaw: Tilting toward immunosuppression. Nat Med 2009; $15: 496-7$.

18. Sousa H, Silva J, Azevedo L, Pinto-Correia AL, Catarino R, Pinto D, et al. Epstein-Barr virus in healthy individuals from Portugal. Acta Med Port 2011;24:707-12.

19. Pierson DL, Stowe RP, Phillips TM, Lugg DJ, Mehta SK. EpsteinBarr virus shedding by astronauts during space flight. Brain Behav Immun 2005;19:235-42.

20. Chêne A, Nylén S, Donati D, Bejarano MT, Kironde F, Wahlgren M, et al. Effect of acute Plasmodium falciparum malaria on reactivation and shedding of the eight human herpes viruses. PLoS One 2011;6:e26266.

21. Larsen M, Sauce D, Deback C, Arnaud L, Mathian A, Miyara M, et al. Exhausted cytotoxic control of Epstein-Barr virus in human lupus. PLoS Pathog 2011;7:e1002328.

22. Binkley PF, Cooke GE, Lesinski A, Taylor M, Chen M, Laskowski B, et al. Evidence for the role of epsteinbarr virus infections in the pathogenesis of acute coronary events. PLoS One 2013;8:e54008.

23. Angelini DF, Serafini B, Piras E, Severa M, Coccia EM, Rosicarelli B, et al. Increased CD8+ T cell response to Epstein-Barr virus lytic antigens in the active phase of multiple sclerosis. PLoS Pathog 2013;9:e1003220.

24. Waldman WJ, Williams MV Jr, Lemeshow S, Binkley P, Guttridge D, Kiecolt-Glaser JK, et al. Epstein-Barr virus-encoded dUTPase enhances proinflammatory cytokine production by macrophages in contact with endothelial cells: Evidence for depression-induced atherosclerotic risk. Brain Behav Immun 2008;22:215-23. 
25. Sauce D, Larsen M, Curnow SJ, Leese AM, Moss PA, Hislop AD, et al. EBV-associated mononucleosis leads to long-term global deficit in T-cell responsiveness to IL-15. Blood 2006;108:11-8.

26. Fletcher JM, Vukmanovic-Stejic M, Dunne PJ, Birch KE, Cook JE, Jackson SE, et al. Cytomegalovirus-specific CD4+ T cells in healthy carriers are continuously driven to replicative exhaustion. J Immunol 2005; 175:8218-25.

27. Vescovini R, Biasini C, Fagnoni FF, Telera AR, Zanlari L, Pedrazzoni M, et al. Massive load of functional effector CD4+ and CD8+ T Cells against Cytomegalovirus in very old subjects. J Immunol 2007;179:4283-91.

28. Stowe RP, Kozlova EV, Yetman DL, Walling DM, Goodwin JS, Glaser R. Chronic herpesvirus reactivation occurs in aging. Exp Gerontol 2007;42:563-70.

29. Cicin-Sain L, Brien JD, Uhrlaub JL, Drabig A, Marandu TF, NikolichZugich J. Cytomegalovirus infection impairs immune responses and accentuates T-cell pool changes observed in mice with aging. PLoS Pathog 2012;8:e1002849.

30. Tang YW, Johnson JE, Browning PJ, Cruz-Gervis RA, Davis A, Graham BS, et al. Herpesvirus DNA is consistently detected in lungs of patients with idiopathic pulmonary fibrosis. J Clin Microbiol 2003;41:2633-40.

31. Kelly BG, Lok SS, Hasleton PS, Egan JJ, Stewart JP. A rearranged form of Epstein-Barr virus DNA is associated with idiopathic pulmonary fibrosis. Am J Respir Crit Care Med 2002;166:510-3.

32. Williams H, Crawford DH. Epstein-Barr virus: The impact of scientific advances on clinical practice. Blood 2006;107:862-9.

33. Simoons-Smit AM, Kraan EM, Beishuizen A, Strack van Schijndel RJ, Vandenbroucke-Grauls CM. Herpes simplex virus type 1 and respiratory disease in critically-ill patients: Real pathogen or innocent bystander? Clin Microbiol Infect 2006;12:1050-9.

34. Cohen JI. Cytomegalovirus in the intensive care unit: Pathogen or passenger? Crit Care Med 2009;37:2095-6.

35. Olsson J, Wikby A, Johansson B, Löfgren S, Nilsson BO, Ferguson FG. Age-related change in peripheral blood T-lymphocyte subpopulations and cytomegalovirus infection in the very old: The Swedish longitudinal OCTO immune study. Mech Ageing Dev 2000;121:187-201

36. Wang GC, Kao WH, Murakami P, Xue QL, Chiou RB, Detrick B, et al. Cytomegalovirus infection and the risk of mortality and frailty in older women: A prospective observational cohort study. Am J Epidemiol 2010;171:1144-52.

37. Linssen CF, Jacobs JA, Stelma FF, van Mook WN, Terporten P, Vink C, et al. Herpes simplex virus load in bronchoalveolar lavage fluid is related to poor outcome in critically ill patients. Intensive Care Med 2008;34:2202-9. 